\title{
Gender Talk: Differences in Interaction Style in CMC
}

\author{
Xiaoning Sun, Susan Wiedenbeck, Thippaya Chintakovid, and Qiping Zhang \\ Drexel University, College of IST, 3141 Chestnut Street Philadelphia PA 19104, USA \\ \{xs27, sw53, tc79, qiping\} @drexel.edu
}

\begin{abstract}
Qualitative analysis was used to investigate the nature of the interactions of different gender pairings doing a negotiation task via computermediated communication (CMC). Preliminary results indicate that female pairs used more language of fairness, saving face, and acknowledgement in their conversation than did male pairs. Male pairs made more procedural statements about meeting management and actions than female pairs. The study provides a preliminary understanding of how gender interactions may affect performance in CMC tasks.
\end{abstract}

\section{Introduction}

A well-known phenomenon to linguists and socio-psychologists is that linguistic styles are relatively different for men and women, and these differences are rooted in different ways of learning speech from childhood [5]. Men tend to be sensitive to the power dynamics of interaction, speaking in direct ways that position themselves as one-up; women tend to react more strongly to the rapport dynamics, speaking in indirect ways that save face for others and avoid putting others in a one-down position [5]. These patterns are also reflected in the ways males and females interact with computers [6]. For example, meta-analysis revealed gender-related stereotypical patterns in CMC environments, in which female communication, compared to male, is more socio-emotionally oriented [2].

Our work on CMC and gender (summarized in Section 3) has shown that gender differences affect trust and performance in computer-mediated tasks [4]. However, there has been little qualitative research on the nature of the interactions of different gender groups that helps explain these results. In this study, we used qualitative methods to take a closer look at the social mechanisms employed by different gender pairings. This work-in-progress provides a preliminary understanding of how gender pair collaboration may affect trust and group performance in two CMC modes, video conferencing (VC) and Instant Messaging (IM).

\section{Methodology}

This study is a $3 \times 2$ between subjects design. The gender pairing factor included male/male (MM), male/female (MF), and female/female (FF) pairs; the media condition factor included VC and IM. In the VC condition gender information was known by passively seeing the partner in the video. In the IM condition, the gender of the partners was revealed by the experimenter immediately before doing their task. 
A total of 120 undergraduate students (60 pairs) took part in the study. Participants were frequent users of IM technology, but less frequent users of VC technology. Pairs of participants did not know each other before the experiment.

Using a negotiation task [7], participants played the roles of marketing managers of two competitive companies in which they had to agree on prices for their three common drugs. The profits were constructed so that for one participant a particular price would bring about great payoff, but the same price created a loss for the other participant. In this situation, the best way to make money overall is to choose a set of three prices that are reciprocally beneficial_-one player will receive a high payoff while the other takes a loss, and then the reverse for another product.

Pairs were run one at a time. Members of a pair were put in different rooms so that they did not see each other face-to-face. They were randomly assigned to perform the task using the VC or IM channel. Pairs had 30 minutes to do the task. Subsequently, they completed a trust questionnaire; the Alpha reliability was .82.

\section{Analysis and Results}

The analysis of the communication process was based on a coding scheme. Initial codes were developed based on the literature of pair negotiation and communication $[1,3]$. Two researchers iteratively refined the codes and rules for their application. Then, they independently coded 18 randomly chosen transcripts. The inter-rater reliability was $91 \%$. Considering the high reliability, one rater coded the rest of the transcripts. Table 1 shows the final coding scheme.

In a previous paper [4], we reported the results of the quantitative analyses of trust and performance. First, we found that female pairs perceived higher levels of trust

Table 1. The coding scheme

\begin{tabular}{|l|l|}
\hline Code Name & Description \\
\hline Fairness & $\begin{array}{l}\text { Evaluative statements considering both parties' benefit. E.g., } \\
\text { "[Drug] Alpha } 2 \text { is not in my best interest but if other prices } \\
\text { work out I am willing to take a loss." }\end{array}$ \\
\hline Clarification & $\begin{array}{l}\text { Statements repeating information already mentioned. E.g., } \\
\text { "You said [Drug] alpha1 is not good for you, right?" }\end{array}$ \\
\hline $\begin{array}{l}\text { Meeting } \\
\text { Management }\end{array}$ & $\begin{array}{l}\text { Statements that move negotiation ahead. E.g., "Where do you } \\
\text { want to start, [Drug] Alpha?" }\end{array}$ \\
\hline Action & $\begin{array}{l}\text { Statements proposing negotiation strategies. E.g., "We should } \\
\text { each come up with a list of [Drug] Alpha strategies that we } \\
\text { would not accept just to narrow things down." }\end{array}$ \\
\hline Saving face & $\begin{array}{l}\text { Statements saying no in an indirect way. E.g., "The price is } \\
\text { not very good to me." }\end{array}$ \\
\hline $\begin{array}{l}\text { Acknowledge- } \\
\text { ment }\end{array}$ & $\begin{array}{l}\text { Statements appreciating partner's work. E.g., "It's nice work- } \\
\text { ing with you." }\end{array}$ \\
\hline Tentative Speech & $\begin{array}{l}\text { Statements asking partner's opinions. E.g., "Do you agree } \\
\text { with me on [Drug] Alpha 6?" }\end{array}$ \\
\hline
\end{tabular}


than male pairs when gender information was passively seen via the VC channel. Second, female pairs perceived higher levels of trust than male pairs when gender information was mutually revealed via the IM channel. Third, male/female pairs had better performance outcomes than female pairs.

To date, communications from a total of 27 out of 60 pairs have been analyzed. For the analysis of the communication process data, we conducted an ANOVA on each code. Table 2 shows the mean of each code frequency and p-value for the MM, FF, and MF pairs. Interaction effects were tested if gender and media were significant. For each gender-media condition, there were 4 or 5 pairs. In the presentation of the results we focus mostly on the MM and FF pairs.

Table 2. Mean and $\mathrm{p}$ value (from ANOVA) of codes among three gender pairings

\begin{tabular}{|c|c|c|c|c|c|c|c|c|c|}
\hline \multirow{2}{*}{} & \multicolumn{2}{|c|}{ FF } & \multicolumn{2}{c|}{ MF } & \multicolumn{2}{c|}{ MM } & \multicolumn{3}{c|}{ p-value } \\
\cline { 2 - 10 } & IM & Video & IM & Video & IM & Video & Gender & Media & Interaction \\
\hline Fairness & 5.8 & 7.8 & 4.8 & 7.0 & 3.2 & 3.5 & $\mathbf{. 0 0}$ & $\mathbf{. 0 4}$ & .48 \\
\hline Clarification & 5.0 & 15.5 & 4.2 & 19.3 & 3.4 & 12.3 & $\mathbf{. 0 1}$ & $\mathbf{. 0 0}$ & $\mathbf{. 0 2}$ \\
\hline $\begin{array}{c}\text { Meeting } \\
\text { Management }\end{array}$ & 3.6 & 5.8 & 2.8 & 8.5 & 3.4 & 2.8 & $\mathbf{. 0 0}$ & $\mathbf{. 0 0}$ & $\mathbf{. 0 0}$ \\
\hline Action & 1.0 & 0.5 & 1.6 & 1.5 & 3.2 & 1.5 & $\mathbf{. 0 2}$ & .09 & --- \\
\hline Saving face & 5.0 & 0.5 & 2.0 & 1.0 & 1.6 & 1.0 & $\mathbf{. 0 1}$ & $\mathbf{. 0 0}$ & $\mathbf{. 0 0}$ \\
\hline $\begin{array}{c}\text { Acknowl- } \\
\text { edgement }\end{array}$ & 2.6 & 0.8 & 0.2 & 0.0 & 2.0 & 0.0 & $\mathbf{. 0 0}$ & $\mathbf{. 0 1}$ & .07 \\
\hline $\begin{array}{c}\text { Tentative } \\
\text { Speech }\end{array}$ & 2.0 & 3.3 & 2.8 & 1.8 & 2.2 & 0.8 & .78 & .53 &.--- \\
\hline
\end{tabular}

There were several gender effects: (1) FF pairs had more collaborative communication language, including fairness $(\mathrm{F}(2,21)=8.94, \mathrm{p}<.00)$, saving face $(\mathrm{F}(2,21)=$ $5.76, \mathrm{p}<.01)$ and acknowledgement $(\mathrm{F}(2,21)=7.93, \mathrm{p}<.00) ;(2) \mathrm{MM}$ pairs used more direct language and more calls for planning and action, including meeting management $(\mathrm{F}(2,21)=14.54, \mathrm{p}<.00)$ and action $(\mathrm{F}(2,21)=4.78, \mathrm{p}<.02)$; (3) FF pairs used more clarification statements $(\mathrm{F}(2,21)=5.50, \mathrm{p}<.01)$. Also, there were media effects of VC on meeting management $(\mathrm{F}(1,21)=37.16, \mathrm{p}<.00)$ and clarification $(\mathrm{F}$ $(1,21)=28.73, \mathrm{p}<.00)$. All pairs did more meeting management and clarification in the video condition. Furthermore, there were also media effects of IM on saving face $(\mathrm{F}(1,21)=25.32, \mathrm{p}<.00)$ and acknowledgement $(\mathrm{F}(1,21)=7.73, \mathrm{p}<.01)$. Overall, pairs used more cooperative language, such as acknowledgement words, in the IM condition. Generally, the MF pairs' conversational behavior in IM fell in between the FF and MM pairs, while in VC the MF pairs' conversational behavior was more variable. There were interaction effects of gender $\mathrm{x}$ media on meeting management $(\mathrm{F}(2$, $21)=21.78, \mathrm{p}<.00)$, clarification $(\mathrm{F}(2,21)=4.48, \mathrm{p}<.02)$ and saving face $(\mathrm{F}(2$, 21) $=18.95, \mathrm{p}<.00)$. 


\section{Discussion and Conclusion}

As discussed above, females tend to use a collaborative conversational style focusing on harmonious relationships, whereas males tend to be sensitive to power in conversational interactions, speaking in direct ways and focusing on status [5]. Our communication process analysis is largely consistent with these ideas, in that FF pairs used more languages of fairness, saving face, and acknowledgement in their conversation; MM pairs used more direct statements about meeting management and action when communicating with each other and were less prone to use a collaborative style.

The qualitative analysis provides more detailed data to explain the results from our previous quantitative analyses, especially with respect to trust [4]. The higher levels of trust perceived by FF pairs in the VC and IM channels may be partly due to the conversational styles they used. It appears that FF pairs tried to create a smooth relationship by considering both parties' benefit and reinforcing that with language expressing mutual respect and appreciation of others' efforts. On the other hand, MM pairs showed lower sensitivity to group harmony in the competitive negotiation context. This may have influenced MM pairs' lower levels of trust. MF pairs' conversational behaviors have been less often studied, and we plan to focus on these mixed pairs in further analysis of these data. Our results are tentative because we have only analyzed about half of the pairs. If the full analysis of 60 pairs shows consistent results, we will have a much clearer understanding of linguistic mechanisms that support collaborators in competitive CMC settings.

In conclusion, it appears clear that gender is a factor that should be considered in CMC. As the workplace becomes more diverse in terms of gender and culture, leaders of virtual teams will need to become even better at interacting with diverse team members and more flexible in adjusting their own styles to different group compositions.

\section{References}

1. Fisher, R., Ertel, D.: Getting ready to negotiate: The getting to YES workbook. Penguin, New York (1995)

2. Li, Q.: Computer-mediated communication and gender difference: a meta-analysis. In: Presented at the Annual Meeting of the American Educational Research Association, Montreal (2005)

3. Rafaeli, S., Sudweeks, F.: ProjectH Codebook. [On-line] (1993), available: archsci.arch.su.edu.au/pub/projectH/coding.docs/ codebook

4. Sun, X., Zhang, Q., Wiedenbeck, S., Chintakovid, T.: The effect of gender on trust perception and performance in computer-mediated virtual environments. In: Proc. ASIS\&T'07 (to appear)

5. Tannen, D.: The power of talk: who gets heard and why. Harvard Business Review 73(5), 138-148 (1995)

6. Turkle, S.: Computational reticence: Why women fear the intimate machine. In Technology and women's voices: Keeping in touch. In: Kramarae, C. (ed.) New York, pp. 41-61 (1988)

7. Zhang, Q.P., Olson, G.M., Olson, J.S.: Does video matter more for long distance collaborators? In: Proc. XXVIII International Congress of Psychology (CD-ROM) (2004) 